\title{
CONTROVERSIES ON VERTEBROPLASTY AND KYPHOPLASTY FOR VERTEBRAL COMPRESSION FRACTURES
}

\author{
CONTROVÉRSIAS EM VERTEBROPLASTIA E CIFOPLASTIA PARA \\ FRATURAS VERTEBRAIS EM COMPRESSÃO \\ CONTROVERSIAS EN VERTEBROPLASTIA Y CIFOPLASTIA PARA \\ FRACTURAS DE COMPRESIÓN VERTEBRAL
}

Alisson Roberto Teles ${ }^{1}$, Tobias Alécio Mattel ${ }^{2}$, Orlando Righesso ${ }^{3}$, Asdrubal Falavigna ${ }^{4}$

\begin{abstract}
Vertebroplasty and kyphoplasty are widely used for osteoporotic and cancer-related vertebral compression fractures refractory to medical treatment. Many aspects of these procedures have been extensively discussed in the literature during the last few years. In this article, we perform a critical appraisal of current evidence on effectiveness and ongoing controversies regarding surgical technique, indications and contraindications, clinical outcomes and potential complications of these procedures.
\end{abstract}

Keywords: Vertebroplasty; Kyphoplasty; Fractures, compression; Osteoporotic fractures; Osteoporosis.

\section{RESUMO}

A vertebroplastia e a cifoplastia têm sido amplamente utilizadas para fraturas por compressão osteoporóticas e relacionadas a tumor refratárias ao tratamento clinico. Nos últimos anos, vários aspectos relacionados a esses procedimentos têm sido amplamente discutidos na literatura. Neste artigo, realizamos uma análise crítica da evidência atual sobre a efetividade desses procedimentos e sobre as controvérsias referentes a técnica cirúrgica, indicações e contraindicações, resultados clínicos e possíveis complicações.

Descritores: Vertebroplastia; Cifoplastia; Fraturas por compressão; Fraturas por osteoporose; Osteoporose.

\section{RESUMEN}

La vertebroplastia y la cifoplastia han sido ampliamente utilizadas en fracturas por compresión osteoporóticas y relacionadas con tumor refractarias al tratamiento clínico. En los últimos años, diversos aspectos relacionados con estos procedimientos han sido ampliamente discutidos en la literatura. En este artículo, presentamos un análisis crítico de la evidencia actual sobre la eficacia y las controversias relativas a la técnica quirúrgica, indicaciones y contraindicaciones, resultados clínicos y posibles complicaciones.

Descriptores: Vertebroplastia; Cifoplastia; Fracturas por compresión; Fracturas osteoporóticas; Osteoporosis.

\section{INTRODUCTION}

Osteoporosis is considered a public health problem worldwide, with increased prevalence as the population ages. ${ }^{1}$ The prevalence of osteoporosis in postmenopausal women in Brazil varies from $15 \%$ to $33 \%{ }^{2}$ Vertebral compression fractures (VCF) are the most common fracture in osteoporotic patients, followed by hip, wrist or ankle fractures, which are a common initial presentation of osteoporosis. ${ }^{3}$ The majority of diagnosed vertebral fractures are due to low energy traumas, related instead to osteoporosis. Specific pathologies and severe trauma account for only $3 \%$ and $14 \%$, respectively, of all clinically evident vertebral fractures in the community. ${ }^{4}$

The prevalence of vertebral fractures in subjects aged 50 to 80 years varies from $7 \%$ to $19 \%$ in women, and from $4 \%$ to $17 \%$ in men, according to radiological studies. ${ }^{5}$ After suffering the first vertebral fracture, the risk of developing new vertebral fractures increases by 5 to 10 times. $^{6}$ Although most VCF heal within a few months with conservative therapy, a significant number fail to improve, and require long-term care or surgical intervention. ${ }^{7}$ Fractures that fail to improve with conservative therapy are often treated with vertebral augmentation procedures (VAP).
VAP refers to vertebroplasty and/or kyphoplasty. Vertebroplasty is a minimally invasive, image-guided procedure that involves injection of cement (typically PMMA) into a fractured vertebral body. Kyphoplasty involves the initial inflation of a balloon tamp that creates a low resistance cavity within the vertebral body, into which cement is subsequently injected.

\section{EFFECTIVENESS OF VERTEBRAL AUGMENTATION PROCEDURES}

The majority of VAP are performed for symptomatic osteoporotic or cancer-related VCF. The primary clinical goals of augmentation are to reduce the pain and disability and enhance the patient's quality of life. It has proven success rates ranging from $80 \%$ to $95 \%$ for osteoporotic fractures, and from $70 \%$ to $92 \%$ for neoplastic fractures. ${ }^{8}$ Following a VAP for vertebral compression fracture, a mean reduction of $5.68( \pm 1.24)$ points is observed in the Visual Analogic Scale of Pain (VAS, from $8.36( \pm 0.78)$ to 2.86 $( \pm 1.09))$, as demonstrated in a meta-analysis of 60 studies published by Eck et al. ${ }^{9}$

1. Universidade de Caxias do Sul, Laboratory of Clinical Studies and Basic Models of Spinal Disorders, Caxias do Sul, RS, Brazil.

2. The Brain \& Spine Center, Invision Health, Buffalo, Department of Neurosurgery, NewYork, USA

3. Hospital Tacchini, Department of Orthopedics, Spine Surgery, Bento Gonçalves, RS, Brazil.

4. Department of Neurosurgery, Universidade de Caxias do Sul, Caxias do Sul, RS, Brazil. 
Vertebral augmentation is an established and safe procedure. Cumulative evidence demonstrates that VAP provides better outcomes than nonsurgical management in randomized clinical trials and meta-analyses. ${ }^{10,11}$ Several large retrospective studies using claims data, investigating vertebroplasty, kyphoplasty and nonsurgical management, provide additional evidence. ${ }^{12}$

Two blinded randomized controlled trials failed to demonstrate an advantage in their respective study populations for vertebroplasty over a placebo intervention (sham procedure) for pain reduction or improvement in disability. ${ }^{13}$ Following the publication of these results in 2009, the use of VAP in the USA reduced significantly. ${ }^{14}$ However, it is argued that those two trials suffered from significant flaws, including atypically broad inclusion criteria, allowance of chronic fractures, small sample size, and high crossover, all of which preclude definitive conclusions. ${ }^{15}$ For example, in the INVEST Trial, ${ }^{16}$ higher crossover in the sham group compared with vertebroplasty (51\% versus $13 \%)$ at 3 months suggest that any short-term effects of the sham intervention are not long-lasting.

Regarding metastasis, the Cancer Patient Fracture Evaluation study ${ }^{17}$ prospectively enrolled patients randomized to treatment by kyphoplasty $(n=70)$ or non-surgical management $(n=64)$. The inclusion criteria included a known diagnosis of cancer, one to three VCFs, a score of more than 4 on the numerical rating scale (NRS) for pain, and a Roland-Morris Disability Questionnaire (RDQ) score of more than 10. Patients with a primary bone tumor, plasmacytoma, or a lesion deemed unsuitable for treatment with kyphoplasty were excluded. A total of 117 patients (kyphoplasty, $n=65$; nonsurgical treatment, $n=52$ ) completed the assigned treatment and had at least 1 month of follow-up. Thirty-seven patients (71\%) crossed over to the kyphoplasty group after 1 month. All the outcome measurements favored the kyphoplasty and crossover groups at all time points, but the statistical significance vanished with time, perhaps because of the relatively few remaining patients in the nonsurgical management group.

\section{COST-EFFECTIVENESS OF VERTEBRAL AUGMENTATION PROCEDURES}

Borgström et al. ${ }^{18}$ recently published a systematic review of the literature in which they identified 5 health economic analyzes evaluating VAPs. As pointed out by the authors, the studies differed widely in terms of study design, modeling framework, and data used. Thus, a meta-analysis could not be performed. Of the five studies reviewed, three showed that VAP is cost-effective when compared with nonsurgical management. If a benefit in mortality reduction were taken into consideration in the analyses, the cost-effectiveness of vertebral augmentation would be even higher. The authors concluded that the currently available evidence from health economic analyses indicate that VAPs are cost effective when compared with nonsurgical management for VCF refractory to initial conservative treatment. No definitive conclusion could be reached regarding the cost effectiveness of vertebroplasty compared to kyphoplasty. ${ }^{18}$

\section{VERTEBROPLASTY VERSUS KYPHOPLASTY}

There is discussion in the literature regarding the effectiveness of kyphoplasty over vertebroplasty and the selection of patients for one or other procedure. In summary, the available evidence demonstrates that they are safe procedures and have similar effectiveness.

Evidence from some meta-analyses suggests that while both procedures have a low complication rate, kyphoplasty may have a lower rate of serious and symptomatic complications. ${ }^{19}$ Ma et al. ${ }^{20}$ in a recent meta-analysis of randomized and non-randomized clinical trials, concluded that both procedures are safe and effective. The also suggest that kyphoplasty could be superior to vertebroplasty in patients with large kyphosis angles, vertebral fissures, fractures in the posterior edge of the vertebral body, or significant height loss in the fractured vertebrae.
More recently, Dohm et al. ${ }^{21}$ published the results of a RCT with a two-year follow-up. Both treatments provided similar sustained improvement from the baseline in terms of pain, disability, and quality of life, with the improvement lasting 2 years. Similar rates of new fractures were observed between the group in the 1- and 2-year follow-up. Surgical and hospitalization times were shorter with vertebroplasty. Kyphoplasty had fewer cement leakages, a trend of longer fracture-free survival, and less loss of kyphotic-deformity correction during the 2-year follow-up. ${ }^{21}$

However, it is currently unclear in which patients these advantages of kyphoplasty over vertebroplasty outweigh its drawbacks, such as higher invasiveness, more extensive anesthesia, and higher costs. ${ }^{22}$ The relationship between vertebral height restoration and clinical outcome has not been established. ${ }^{23}$ Also, a follow-up of height loss after VAP demonstrated the loss to be greater in kyphoplasty, due to homogeneous distribution of cement, than in vertebroplasty. ${ }^{24}$ Therefore, height recovery differences tend to vanish with time.24

Specifically in cancer-related fractures, Schroeder et al. ${ }^{25}$ reviewed the literature regarding the safety and efficacy of both techniques, and found similar results. In a pooled analysis of published case series in patients with multiple myeloma, Khan et al. $^{26}$ found similar clinical results comparing vertebroplasty and kyphoplasty.

\section{INDICATIONS AND CONTRA-INDICATIONS}

More than $95 \%$ of indications for VAP are related to symptomatic osteoporotic VCF refractory to medical therapy or with unacceptable medical therapy side effects, vertebral bodies weakened by neoplasm, and symptomatic vertebral body microfractures, as documented by magnetic resonance image (MRI) or nuclear imaging, and/ or lytic lesions identified on computed tomography (CT), without obvious loss of vertebral body height. ${ }^{27}$ Other indications include enhancement of fixation in osteoporotic ${ }^{28}$ or cancer patients ${ }^{29}$ and vertebral hemangiomas. ${ }^{30}$ There are also some reports on VAP in the treatment of burst fractures ${ }^{31}$ and painful Schmorl nodes. ${ }^{32}$ Absolute contraindications include active infection, whether locally or systemically, uncorrected coagulopathy, and allergy to bone cement or opacification agent. ${ }^{33}$ Current use of platelet-inhibiting agents also increases the risk of bleeding, but it has been considered a relative contraindication, and, if anticoagulants or platelet inhibiting agents cannot be discontinued, it is still possible to perform vertebroplasty in the face of a pressing clinical indication. Age should not be considered a contraindication. Although severe body compression was a relative contraindication in the past, results of recent studies have shown that patients with vertebra plana can also benefit from VAP. ${ }^{34}$

Involvement of the posterior vertebral body wall has been considered a relative contraindication to VAP in osteoporotic VCF. Recently, some authors have demonstrated good clinical results and low complication rates using VAP in these patients. ${ }^{35}$ For example, Nakano et al. ${ }^{36}$ compared the clinical and radiological results of 40 patients with osteoporotic burst fractures submitted to vertebroplasty with 40 historical controls submitted to medical treatment. The existence of posterior wall defects of the fractured vertebral body was determined by CT and MRI. Better clinical and radiological results were observed in the surgical group compared with non-operative treatment. In addition, the authors observed a low rate of cement leakage (10\%), and no neurologic deficit, cement embolism or infection. ${ }^{37}$

Oncological patients with symptomatic spinal cord compression secondary to a VCF should firstly be decompressed and stabilized. ${ }^{38}$ Patients with asymptomatic encroachment on the spinal cord are at increased risk of adverse events in the case of significant cement leakage, but can usually still be successfully treated by VAP. ${ }^{35}$ These patients should be operated under neuromonitoring or local anesthesia with an anterior delivery of cement, similarly to those with upper thoracic or cervical spine fractures. ${ }^{39}$

Recently, Sun et al. ${ }^{40}$ reviewed the results of vertebroplasty for painful spinal metastasis in 43 patients with epidural encroachment in whom open surgery was not available due to poor general medical status and limited life expectancy. In this series, 
$32 \%$ presented signs of cord or cauda equina compression preoperatively. On post-procedural CT images, the percentage of lesion filling with bone cement was more than $50 \%$ in all levels. In spite of cement leakage being observed in $69 \%$ of patients, no deterioration of spinal cord or cauda equina compression symptoms was observed in any patients. ${ }^{40}$

\section{CEMENT}

PMMA is the most common used in VAP. ${ }^{41}$ Several inherent advantages, including bio-inertness, ease of handling, good biomechanical strength, and cost-effectiveness, make PMMA an ideal choice for bone cement. PMMA is a low-viscosity acrylic bone cement to which a radio-opaque substance such as barium, tantalium or tungsten sulphate has been added to facilitate visualization during the procedure. It is prepared by mixing a liquid component containing the monomer, accelerator and inhibitor with a powder containing the polymer, radio-opacifier and initiator.

Recently, new biological materials have been introduced as alternatives to PMMA, such as calcium phosphate and hydroxyapatite. These are not exothermic, allowing the deposition of new bone that could eventually replace the cement. Nevertheless, biological cements are still expensive, and their manipulation is not easy, due to their high viscosity that hinders interstitial diffusion inside the vertebral body. ${ }^{42}$ These materials have been recommended in high-energy fractures in young patients, ${ }^{37}$ although other authors find a high rate of mechanical failure with these materials, due to their lower resistance to shear, flexion and distraction forces. ${ }^{43}$

Theoretical mechanisms involved in pain relief after VAP have been proposed as being related to vertebral body stabilization of micro-movements and prevention of progressive vertebral collapse. In this sense, it is reasonable to think that the more cement safely injected, the better results in terms of stability and pain relief. Other theories proposed in the past, such as thermal necrosis of the surrounding tissues and nerve ends, and chemical toxicity of the PMMA, have been put in doubt in recent studies. ${ }^{44}$ There is sill debate in the literature regarding the volume needed in VAP.

Some biomechanical studies have demonstrated that a minimal cement volume or cemented vertebral body volume fraction is required to restore the mechanical properties of the fractured vertebra. ${ }^{45}$ Liebshner et al. ${ }^{46}$ suggest that filling as little as $14 \%$ of vertebral body, or $3.5 \mathrm{~mL}$, is sufficient to restore vertebral stiffness. Early clinical studies that attempted to verify the relationship between volume of cement and clinical outcome failed to identify a relationship between volume of injected cement and pain relief. ${ }^{47}$

Jin et al. ${ }^{48}$ first identified a possible relationship between increase in volume fraction and clinical outcome. More recently, in the study of Nieuwenhuijse et al., ${ }^{49}$ a total of 106 patients with 196 treated vertebral compression fractures were followed up in relation to back pain and occurrence of new vertebral compression fractures in the first year. The authors classified patients as responders (average postoperative back pain $\leq 6$ ) and nonresponders (average postoperative back pain $>6$ ). The cemented fraction of the vertebral body was determined using volumetric analysis of the postoperative CT scan of the treated levels. The mean intravertebral cement volume was $3.94 \mathrm{~mL}$ (range $0.13-10.8 \mathrm{~mL}$ ). The mean cemented vertebral body fraction was significantly lower in nonresponders (15\% versus $21 \%, P=0.002)$. A vertebral body fraction of $24 \%$ was identified as the optimal fraction to be cemented. This fraction corresponded to $93 \%$ to $100 \%$ specificity for achieving pain relief, without being significantly associated with a higher risk of occurrence of cement leakage or new vertebral compression fractures. ${ }^{49}$

Finally, Roder et al. ${ }^{50}$ found that the most important modifiable predictor for pain relief was cement volume, with a dose-dependent reduction in pain. In their study, volumes higher than $4.5 \mathrm{~mL}$ were associated with better clinical results. ${ }^{50}$ Other recent studies report that cement volume is of the utmost importance for correcting deformities and maintaining vertebral height. ${ }^{51}$

Sun et al. ${ }^{40}$ recently published their experience with 43 patients with spinal metastasis and epidural compression treated with percutaneous vertebroplasty. In this report, they state that the stopping point is determined when the cement reaches the posterior quarter of the vertebral body. Also, the injection should be immediately terminated if the patient, under local anesthesia, complains of any pain, such as radicular pain, which could be due to pressure on the posterior neurological structures.

\section{BILATERAL VERSUS UNILATERAL APPROACH}

Traditionally, VAP have been performed by bilateral pedicular approaches. ${ }^{52}$ More recently, unilateral transpedicular approach have been increasingly used by spine surgeons and interventional radiologists. ${ }^{53}$ Also, a unilateral extra-pedicular approach has been described in the literature with good results. ${ }^{39}$ The unilateral transpedicular approach has been proposed in order to reduce operative time, costs, radiation exposure and risk of medial pedicular violations. ${ }^{54}$ Another theoretical benefit of the unilateral approach is that it reduces the possibility of cement leakage through the canula tract, which could cause nerve injury. ${ }^{53}$ Biomechanical studies suggest that vertebroplasty via unipedicular approach provides comparable restoration of vertebral body stiffness when compared with a bilateral approach..$^{55}$

The unilateral approach has been advocated, particularly in patients with malignant vertebral fractures, in whom pain relief is the main goal of the procedure and multiple levels are usually performed, with the objective of reducing operative time and radiation exposure. ${ }^{56}$ As proposed by Papanastassiou et al., ${ }^{56}$ a preoperative planning with MRI would help to determine the feasibility of unipedicular approach: a transpedicular trajectory should reach the midline at the middle or anterior third of the vertebral body without violating the medial wall of pedicle. However, in case of unsatisfactory filling (cement not crossing the midline), bilateral canullation could be performed. ${ }^{57}$

Several clinical studies have been published addressing the unipediclar versus bipedicular approach in VAP. Yang et al. ${ }^{58}$ analyzed 4 low quality RCT with a total of 159 patients, and found no difference between unilateral and bilateral transpedicular kyphoplasty in terms of pain relief, whether in the short-term or long-term follow-up, rate of adjacent vertebral fracture, cement leakage, or loss of vertebral height in long-term follow-up. Operation time and volume of cement were significantly lower in the unipedicular kyphoplasty group. ${ }^{58}$ More recently, Huang et al. ${ }^{59}$ published a meta-analysis of 5 low quality RCT. The authors also found no differences between the two approaches, in regard to clinical outcomes, complications such as cement leakage and adjacent vertebral fractures, kyphosis angle reduction, or anterior vertebral height restoration. Again, they observed lower surgical time in the group of unilateral approach (minimum difference of 24.98 minutos; $P=0.0001$ )

More recently, Zhang et al. ${ }^{60}$ published the results of their small RCT comparing unilateral $(n=36)$ versus bilateral $(n=32)$ percutaneous vertebroplasty in the treatment of acute VCF. They found that cement leakage occurred in $52.7 \%$ of patients who received unilateral puncture versus $28.1 \%$ in the bilateral group $(P<0.05)$. No adverse events were observed. No difference in pain and quality of life was observed at 1-week follow-up. However, the authors identified statistically significant differences in pain and quality of life at 3,6 and 12 months of follow-up, with better results in the bilateral approach group. It is important to note that these statistically significant differences are not clinically significant. Conversely, in another recent small RCT, Chen et al. ${ }^{61}$ found $39 \%$ of cement leakage in the unilateral group, versus $71 \%$ in bilateral group $(P=0.032)$; all patients were asymptomatic. In their study, no differences in clinical outcomes were observed at 2 weeks and 2 years. The unilateral group had less operative time $(31.12 \times 52.34$ minutes; $P<0.001)$ and less amount of cement injected $(3.17 \times 4.36 \mathrm{~mL} ; \mathrm{P}<0.001)$. 


\section{IMPORTANCE OF IMAGING EXAMS}

Magnetic resonance image (MRI) is essential in the preoperative evaluation of patient with suspected osteoporotic or malignant vertebral fracture. ${ }^{62}$ It can accurately confirm the presence and location of acute or subacute nonhealed vertebral fractures, assess the morphology, and rule out the existence of concomitant disease that may preclude VAP. Additionally, radiographically occult vertebral fractures may be detected on MRI, helping to avoid incomplete therapy. CT is helpful in identifying the potential route of cement extravasations by demonstrating any open fracture lines and osseous destruction, especially in pathologic fractures. ${ }^{63}$

Some features of the MRI demonstrate the acute or subacute nature of vertebral fractures in addition to anatomical vertebral collapse. ${ }^{62}$ Due to the presence of bone marrow edema, acute, subacute, or non-healing vertebral fracture appear with a hypointense signal on T1-weighted images, hyper or heterogeneous intensity on T2-weighted images, and hyper-intensity on fat-suppressed T2-weighted images or on short T1 inversion recovery (STIR) sequences where fluid represents marrow edema. However, it is also known that some patients without bone edema on MRI can also benefit from VAP. ${ }^{64}$

For patients with multiple fractures who are unable to submit to $\mathrm{MRI}$, correlation of the CT with a bone scan may be helpful in selecting the vertebral segments that are more likely to respond to augmentation procedures. ${ }^{65}$

For patients who do not show a response to VAP with significantly decreased pain, or experience early relapse of similar pain, additional or repeat imaging evaluation should be performed to determine the cause of treatment failure. ${ }^{66}$ It is important to be aware of the expected imaging changes in previously augmented vertebrae. Persistent edema and interval height loss after a successful vertebral augmentation should not be interpreted as sufficient evidence of ongoing abnormality at the treated vertebral level. To make an accurate diagnosis, it is of vital importance to apply the knowledge of expected imaging changes in treated vertebrae, and correlate post-vertebral augmentation imaging findings with new clinical symptoms and the physical examination. Changes in the MRI after augmentation procedures can be categorized as: (1) signal changes from cement material, such as low signal intensity on T1-weighted and T2-weighted sequences; (2) signal changes in bone marrow surrounding the cement material, which are represented by gradual reduction in edema; and (3) vertebral size and morphology changes resulting from the injection of the cement. ${ }^{66}$

\section{IMPORTANCE OF ROUTINE BIOPSY}

The most common causes of vertebral fractures are osteoporosis or malignancy. Often, malignant fracture can mimic an osteoporotic compression fracture in radiographic image exams. ${ }^{67}$ Meanwhile, patients with known malignancy can present with osteoporotic fractures. $^{68}$ In fact, diagnosing a malignant fracture in a patient without cancer history can be difficult. ${ }^{69}$ For these reasons, some authors advocate that biopsy should be routinely performed, as this does not add significant morbidity or operative time to the procedure. ${ }^{70}$

Recently, Mukhrjee et al. ${ }^{71}$ demonstrated their experience of routine biopsy in vertebroplasty, and observed that $4.7 \%$ of patients with absence of malignant features in clinical and radiological assessments were found to have malignant vertebral compression fracture. The also found that $10 \%$ of oncological patients in complete remission were found to have active malignant disease on biopsy. Other studies observed incidences ranging from $0.4 \%^{72}$ to $6 \%^{73}$ in routine biopsy during vertebral augmentation procedures.

\section{COMPLICATIONS OF VERTEBRAL AUGMENTATION PROCEDURES}

Less than $1 \%$ of patients treated for compression fractures secondary to osteoporosis, and less than $5 \%$ of patients treated who have neoplastic involvement, suffer major complications. ${ }^{27}$ Perivertebral cement leakage is a common occurrence, and can be observed inthe CT in as many as $88 \%$ of cases. ${ }^{74}$ The majority of cases are asymptomatic, and late cement migration to the lungs is rare. As a result, routine post-procedural chest CT is unnecessary in majority of cases. ${ }^{74}$

Cement extravasation into the spinal canal or neuroforamen is rare $(0.4 \% \text { to } 4 \%)^{75}$ and often asymptomatic or transient, but it is important to recognize when this occurs, as it may result in painful radiculopathy and weakness. If high enough to affect the spinal cord or conus medullaris, it can even cause paraparesis, which is an emergency and requires surgical decompression. ${ }^{76}$

Less frequent complications include allergic or idiosyncratic reaction, significant hemorrhage or vascular injury, symptomatic hemothorax or pneumothorac, infection, and death. ${ }^{27}$ In the study of Abdelrahman et al., ${ }^{77}$ the infection rate after VAP was $0.46 \%$.

One major concern after a VAP is the risk of subsequent fracture. The incidence of VCFs following a VAP ranges from with an incidence of $11 \%$ to $52 \%$. $^{78}$ Some authors believe these subsequent fractures are a consequence of the increased stiffness of the treated vertebra, related to the amount of injected cement or, alternately, to cement leakage in the adjacent vertebral disk space. ${ }^{79}$ However, it is more likely that these subsequent fractures are related to the natural history of osteoporosis than to the VAP. ${ }^{80}$ In fact, in a recent meta-analysis of the literature, Song et al found no differences in the incidence of secondary fractures in patients who underwent VAP and patients who underwent conservative treatment for osteoporotic VCF.81

Sun et al. ${ }^{82}$ retrospectively studied the risk factors of subsequent fracture in a cohort of patients who underwent first-time, single-level vertebroplasty. Of 175 patients, 37 (21.1\%) developed subsequent fractures requiring VAP within 12 months of the first procedure. The mean time to subsequent fracture was 85.5 days, and $81 \%$ of them developed within 6 months of the procedures. Identified risk factors for subsequent symptomatic vertebral fracture were low bone mineral density (BMD) and location of treated level at the thoracolumbar junction. The average BMD T-score was $-3.4 \pm 1.5$ in patients with subsequent fractures and $-2.9 \pm 1.6$ in patients without subsequent fractures. The percentage of subsequent fractures was 13.9\% (10 of 72) for treated vertebrae located in the non-thoracolumbar junction, and $26.2 \%$ (27 of 103 ) for those located in the thoracolumbar junction. Ma et al., ${ }^{83}$ in a systematic review of the literature identified that risk factors include lower BMD, lower body mass index, intradiscal cement leakage, and vertebral height restoration, number of pre-existing vertebral fractures, thoracolumbar junction in initial VCFs, cement distraction, older age, and number of treated vertebrae.

\section{FINAL CONSIDERATIONS}

VAPs are safe and effective in pain relief in patients with osteoporotic and tumor-associated VCFs refractory to medical treatment. Economic analyses of healthcare have shown that these procedures are cost-effective compared to nonsurgical treatment. The best existing evidence does not support clinical superiority of kyphoplasty over vertebroplasty for osteoporotic or tumor-associated VCF. PMMA is currently the cement of choice for the treatment of osteoporotic and cancer-related VCF. The volume of injected cement is a subject of debate in the literature; however it seems reasonable to consider attempting to achieve maximum filling in a safe manner (maximum of $10 \mathrm{~mL}$ ), taking care to prevent leakage of cement. The literature demonstrates that in the majority of the cases, good filling of the vertebral body can be achieved with the unilateral pedicular approach. Biopsy should be routinely performed in patients undergoing VAP for VCF.

\section{ACKNOWLEDGMENT}

\section{AOSpine Latin America.}

All authors declare no potential conflict of interest concerning this article. 


\section{REFERENCES}

1. Melton LJ 3rd. Epidemiology of spinal osteoporosis. Spine (Phila Pa 1976). 1997;22(Suppl 24):2S-11S.

2. Baccaro LF, Conde DM, Costa-Paiva L, Pinto-Neto AM. The epidemiology and management of postmenopausal osteoporosis: a viewpoint from Brazil. Clin Interv Aging. 2015:10:583-91.

3. Cummings SR, Melton LJ. Epidemiology and outcomes of osteoporotic fractures. Lancet. 2002;359(9319):1761-7.

4. Cooper C, Atkinson EJ, O'Fallon WM, Melton LJ 3rd. Incidence of clinically diagnosed vertebral fractures: a population-based study in Rochester, Minnesota, 1985-1989. J Bone Miner Res. 1992;7(2):221-7.

5. Leidig-Bruckner G, Limberg B, Felsenberg D, Bruckner T, Holder S, Kather A, et al. Sex difference in the validity of vertebral deformities as an index of prevalent vertebral osteoporotic fractures: a population survey of older men and women. Osteoporos Int. 2000;11(2):102-19.

6. Lindsay R, Silverman SL, Cooper C, Hanley DA, Barton I, Broy SB, et al. Risk of new vertebral fracture in the year following a fracture. JAMA. 2001;285(3):320-3.

7. Kanis JA, Johnell O. The burden of osteoporosis. J Endocrinol Invest. 1999;22(8):583-8.

8. Muto M, Muto E, Izzo R, Diano AA, Lavanga A, Di Furia U. Vertebroplasty in the treatment of back pain. Radiol Med. 2005:109(3):208-19.

9. Eck JC, Nachtigall D, Humphreys SC, Hodges SD. Comparison of vertebroplasty and balloon kyphoplasty for treatment of vertebral compression fractures: a meta-analysis of the literature. Spine J. 2008:8(3):488-97.

10. Wardlaw D, Cummings SR, Van Meirhaeghe J, Bastian L, Tillman JB, Ranstam J, et al. Efficacy and safety of balloon kyphoplasty compared with non-surgical care for vertebral compression fracture (FREE): a randomised controlled trial. Lancet. 2009:373(9668):1016-24.

11. Klazen CA, Lohle PN, de Vries J, Jansen FH, Tielbeek AV, Blonk MC, et al. Vertebroplasty versus conservative treatment in acute osteoporotic vertebral compression fractures (Vertos II): an open-label randomised trial. Lancet. 2010;376(9746):1085-92.

12. Chen AT, Cohen DB, Skolasky RL. Impact of nonoperative treatment, vertebroplasty, and kyphoplasty on survival and morbidity after vertebral compression fracture in the medicare population. J Bone Joint Surg Am. 2013;95(19):1729-36.

13. Buchbinder R, Osborne RH, Ebeling PR, Wark JD, Mitchell P, Wriedt $C$, et al. A randomized trial of vertebroplasty for painful osteoporotic vertebral fractures. N Engl J Med. 2009;361(6):557-68.

14. Goz V, Errico TJ, Weinreb JH, Koehler SM, Hecht AC, Lafage V, et al. Vertebroplasty and kyphoplasty: national outcomes and trends in utilization from 2005 through 2010. Spine J. 2015;15(5):959-65

15. Clark W, Lyon S, Burnes J. Trials of vertebroplasty for vertebral fractures. N Engl J Med. 2009:361(21):2097-8.

16. Kallmes DF, Comstock BA, Heagerty PJ, Turner JA, Wilson DJ, Diamond TH, et al. A randomized trial of vertebroplasty for osteoporotic spinal fractures. N Engl J Med. 2009;361(6):569-79.

17. Berenson J, Pflugmacher R, Jarzem P, Zonder J, Schechtman K, Tillman JB, et al. Balloon kyphoplasty versus non-surgical fracture management for treatment of painful vertebral body compression fractures in patients with cancer: a multicentre, randomised controlled trial. Lancet Oncol. 2011;12(3):225-35.

18. Borgström F, Beall DP, Berven S, Boonen S, Christie S, Kallmes DF, et al. Health economic aspects of vertebral augmentation procedures. Osteoporos Int. 2015;26(4):1239-49.

19. Hulme PA, Krebs J, Ferguson SJ, Berlemann U. Vertebroplasty and kyphoplasty: a systematic review of 69 clinical studies. Spine (Phila Pa 1976). 2006;31(17):1983-2001.

20. Ma XL, Xing D, Ma JX, XuWG, Wang J, Chen Y. Balloon kyphoplasty versus percutaneous vertebroplasty in treating osteoporotic vertebral compression fracture: grading the evidence through a systematic review and meta-analysis. Eur Spine J. 2012;21(9):1844-59.

21. Dohm M, Black CM, Dacre A, Tillman JB, Fueredi G; KAVIAR investigators. A randomized trial comparing balloon kyphoplasty and vertebroplasty for vertebral compression fractures due to osteoporosis. AJNR Am J Neuroradiol. 2014;35(12):2227-36.

22. Anselmetti GC, Muto M, Guglielmi G, Masala S. Percutaneous vertebroplasty or kyphoplasty. Radiol Clin North Am. 2010;48(3):641-9.

23. Feltes C, Fountas KN, Machinis T, Nikolakakos LG, Dimopoulos V, Davydov R, et al. Immediate and early postoperative pain relief after kyphoplasty without significant restoration of vertebral body height in acute osteoporotic vertebral fractures. Neurosurg Focus. 2005;18(3):e5

24. McCall T, Cole C, Dailey A. Vertebroplasty and kyphoplasty: a comparative review of efficacy and adverse events. Curr Rev Musculoskelet Med. 2008;1(1):17-23.

25. Schroeder JE, Ecker E, Skelly AC, Kaplan L. Cement augmentation in spinal tumors: a systematic review comparing vertebroplasty and kyphoplasty. Evid Based Spine Care J. 2011;2(4):35-43.

26. Khan OA, BrinjikjiW, Kallmes DF. Vertebral augmentation in patients with multiple myeloma: a pooled analysis of published case series. AJNR Am J Neuroradiol. 2014;35(1):207-10.

27. Baerlocher MO, Saad WE, Dariushnia S, Barr JD, McGraw JK, Nikolic B, et al. Quality improvement guidelines for percutaneous vertebroplasty. J Vasc Interv Radiol. 2014:25(2):165-70

28. Burval DJ, McLain RF, Milks R, Inceoglu S. Primary pedicle screw augmentation in osteoporotic lumbar vertebrae: biomechanical analysis of pedicle fixation strength. Spine (Phila Pa 1976). 2007:32(10):1077-83

29. Mattei TA, Mendel E, Bourekas EC. Postoperative cement augmentation after 360-degree fixation for highly unstable vertebral fractures in patients with multiple myeloma: a technical note on delayed trans-instrumentation vertebroplasty. World Neurosurg. 2014:82(3-4):537.e1-8.

30. Hao J, Hu Z. Percutaneous cement vertebroplasty in the treatment of symptomatic vertebral hemangiomas. Pain Physician. 2012;15(1):43-9.

31. Stoffel M, Wolf I, Ringel F, Stüer $C$, Urbach H, Meyer B. Treatment of painful osteoporotic compression and burst fractures using kyphoplasty: a prospective observational design. J Neurosurg Spine. 2007;6(4):313-9.
32. Mattei TA, Rehman AA. Schmorl's nodes: current pathophysiological, diagnostic, and therapeutic paradigms. Neurosurg Rev. 2014:37(1):39-46.

33. Hussein MA, Vrionis FD, Allison R, Berenson J, Berven S, Erdem E, et al. The role of vertebral augmentation in multiple myeloma: International Myeloma Working Group Consensus Statement. Leukemia. 2008:22(8):1479-84

34. Peh WC, Gilula LA, Peck DD. Percutaneous vertebroplasty for severe osteoporotic vertebral body compression fractures. Radiology. 2002;223(1):121-6.

35. Hentschel SJ, Burton AW, Fourney DR, Rhines LD, Mendel E. Percutaneous vertebroplasty and kyphoplasty performed at a cancer center: refuting proposed contraindications. $J$ Neurosurg Spine. 2005;2(4):436-40

36. Nakano M, Kawaguchi Y, Kimura T, Hirano N. Transpedicular vertebroplasty after intravertebral cavity formation versus conservative treatment for osteoporotic burst fractures. Spine J. 2014;14(1):39-48

37. Nakano M, Hirano N, Ishihara $H$, Kawaguchi Y, Watanabe $H$, Matsuura K. Calcium phosphate cement-based vertebroplasty compared with conservative treatment for osteoporotic compression fractures: a matched case-control study. J Neurosurg Spine. 2006;4(2):110-7.

38. Papanastassiou ID, Filis AK, Gerochristou MA, Vrionis FD. Controversial issues in kyphoplasty and vertebroplasty in malignant vertebral fractures. Câncer Control. 2014:21(2):151-7.

39. Han KR, Kim C, Eun JS, Chung YS. Extrapedicular approach of percutaneous vertebroplasty in the treatment of upper and mid-thoracic vertebral compression fracture. Acta Radiol. 2005:46(3):280-7.

40. Sun G, Li L, Jin P, Liu XW, Li M. Percutaneous vertebroplasty for painful spinal metastasis with epidural encroachment. J Surg Oncol. 2014;110(2):123-8.

41. Guarnieri G, Masala S, Muto M. Update of vertebral cementoplasty in porotic patients. Interv Neuroradiol. 2015;21(3):372-80.

42. Grafe IA, Baier M, Nöldge G, Weiss C, Da Fonseca K, Hillmeier J, et al. Calcium-phosphate and polymethylmethacrylate cement in long-term outcome after kyphoplasty of painful osteoporotic vertebral fractures. Spine (Phila Pa 1976). 2008:33(11):1284-90.

43. Blattert TR, Jestaedt L, Weckbach A. Suitability of a calcium phosphate cement in osteoporotic vertebral body fracture augmentation: a controlled, randomized, clinical trial of balloon kyphoplasty comparing calcium phosphate versus polymethylmethacrylate. Spine (Phila Pa 1976). 2009;34(2):108-14

44. Verlaan JJ, Oner FC, Slootweg PJ, Verbout AJ, Dhert WJ. Histologic changes after vertebroplasty. J Bone Joint Surg Am. 2004:86-A(6):1230-8.

45. Belkoff SM, Mathis JM, Jasper LE, Deramond $H$. The biomechanics of vertebroplasty. The effect of cement volume on mechanical behavior. Spine (Phila Pa 1976). 2001;26(14):1537-41.

46. Liebschner MA, Rosenberg WS, KeavenyTM. Effects of bone cement volume and distribution on vertebral stiffness after vertebroplasty. Spine (Phila Pa 1976). 2001:26(14):1547-54.

47. Hodler J, Peck D, Gilula LA. Midterm outcome after vertebroplasty: predictive value of technical and patient-related factors. Radiology. 2003;227(3):662-8.

48. Jin YJ, Yoon SH, Park KW, Chung SK, Kim KJ, Yeom JS, et al. The volumetric analysis of cement in vertebroplasty: relationship with clinical outcome and complications. Spine (Phila Pa 1976). 2011;36(12):E761-72.

49. Nieuwenhuiise MJ, Bollen L, van Erkel AR, Dijkstra PD. Optimal intravertebral cement volume in percutaneous vertebroplasty for painful osteoporotic vertebral compression fractures. Spine 2012;37:1747-55. Spine (Phila Pa 1976). 2013;38(4):372.

50. Röder C, Boszczyk B, Perler G, Aghayev E, Külling F, Maestretti G. Cement volume is the most important modifiable predictor for pain relief in BKP: results from SWISSspine, a nationwide registry. Eur Spine J. 2013;22(10):2241-8.

51. Krüger A, Baroud G, Noriega D, Figiel J, Dorschel C, Ruchholtz S, et al. Height restoration and maintenance after treating unstable osteoporotic vertebral compression fractures by cement augmentation is dependent on the cement volume used. Clin Biomech (Bristol, Avon). 2013;28(7):725-30

52. Deramond H, Depriester C, Galibert P, Le Gars D. Percutaneous vertebroplasty with polymethylmethacrylate. Technique, indications, and results. Radiol Clin North Am. 1998;36(3):533-46.

53. Lee SB, Cho KS, Huh PW, Yoo DS, Kang SG, Kim DS, et al Clinical and radiographic results of unilateral transpedicular balloon kyphoplasty for the treatment of osteoporotic vertebral compression fractures. Acta Neurochir Suppl. 2008;101:157-60.

54. Hoh BL, Rabinov JD, Pryor JC, Hirsch JA. Balloon kyphoplasty for vertebral compression fracture using a unilateral balloon tamp via a uni-pedicular approach: technical note. Pain Physician. 2004;7(1):111-4.

55. Tohmeh AG, Mathis JM, Fenton DC, Levine AM, Belkoff SM. Biomechanical efficacy of unipedicular versus bipedicular vertebroplasty for the management of osteoporotic compression fractures. Spine (Phila Pa 1976). 1999;24(17):1772-6.

56. Papanastassiou ID, Eleraky M, Murtagh R, Kokkalis ZT, Gerochristou M, Vrionis FD. Comparison of Unilateral versus Bilateral Kyphoplasty in Multiple Myeloma Patients and the Importance of Preoperative Planning. Asian Spine J. 2014;8(3):244-52

57. Chen B, LiY, Xie D, Yang X, Zheng Z. Comparison of unipedicular and bipedicular kyphoplasty on the stiffness and biomechanical balance of compression fractured vertebrae. Eur Spine J. 2011;20(8):1272-80.

58. Yang $L Y$, Wang $X L$, Zhou L, Fu Q. A systematic review and meta-analysis of randomized controlled trials of unilateral versus bilateral kyphoplasty for osteoporotic vertebral compression fractures. Pain Physician. 2013:16(4):277-90.

59. Huang Z, Wan S, Ning L, Han S. Is unilateral kyphoplasty as effective and safe as bilateral kyphoplasties for osteoporotic vertebral compression fractures? A meta-analysis. Clin Orthop Relat Res. 2014;472(9):2833-42.

60. Zhang LG, Gu X, Zhang HL, Zhang QG, Cai XB, Tao K. Unilateral or bilateral percutaneous vertebroplasty for acute osteoporotic vertebral fracture: a prospective study. J Spinal Disord Tech. 2015;28(2):E85-8

61. Chen C, Bian J, Zhang W, Zhang W, Zhao C, Wei H. Unilateral versus bilateral vertebroplasty for severe osteoporotic vertebral compression fractures. J Spinal Disord Tech. 2014;27(8):E301-4 
62. Do HM. Magnetic resonance imaging in the evaluation of patients for percutaneous vertebroplasty. Top Magn Reson Imaging. 2000;11(4):235-44.

63. Murphy KJ, Deramond H. Percutaneous vertebroplasty in benign and malignant disease. Neuroimaging Clin N Am. 2000;10(3):535-45.

64. Voormolen MH, van Rooij WJ, Sluzewski M, van der GraafY, Lampmann LE, Lohle, et al Pain response in the first trimester after percutaneous vertebroplasty in patients with osteoporotic vertebral compression fractures with or without bone marrow edema. AJNR Am J Neuroradiol. 2006;27(7):1579-85

65. Maynard AS, Jensen ME, Schweickert PA, Marx WF, Short JG, Kallmes DF. Value of bone scan imaging in predicting pain relief from percutaneous vertebroplasty in osteoporotic vertebral fractures. AJNR Am J Neuroradiol. 2000;21(10):1807-12.

66. Kathuria S. Post-vertebral augmentation spine imaging. Neuroimaging Clin N Am. 2014;24(2):337-47.

67. Ho CS, Choi WM, Chen CY, Chen WY, Chan WP. Metastasis in vértebra mimicking acute compression fractures in a patient with osteoporosis: MRI findings. Clin Imaging. 2005;29(1):64-7.

68. Tan SB, Kozak JA, Mawad ME. The limitations of magnetic resonance imaging in the diagnosis of pathologic vertebral fractures. Spine (Phila Pa 1976). 1991;16(8):919-23.

69. An HS, Andreshak TG, Nguyen C, Williams A, Daniels D. Can we distinguish between benign versus malignant compression fractures of the spine by magnetic resonance imaging? Spine (Phila Pa 1976). 1995;20(16):1776-82.

70. Muijs SP, Akkermans PA, van Erkel AR, Dijkstra SD. The value of routinely performing a bone biopsy during percutaneous vertebroplasty in treatment of osteoporotic vertebral compression fractures. Spine (Phila Pa 1976). 2009:34(22):2395-9.

71. Mukherjee S, Thakur B, Bhagawati D, Bhagawati D, Akmal S, Arzoglou V, et al. Utility of routine biopsy at vertebroplasty in the management of vertebral compression fractures: a tertiary center experience. J Neurosurg Spine. 2014:21(5):687-97.

72. Zhang L, Li J, Yang H, Luo Z, Zou J. Histological evaluation of bone biopsy results during PVP or PKP of vertebral compression fractures. Oncol Lett. 2013:5(1):135-138.

73. Schoenfeld AJ, Dinicola NJ, Ehrler DM, Koerber A, Paxos M, Shorten SD, et al. Retros- pective review of biopsy results following percutaneous fixation of vertebral compression fractures. Injury. 2008;39(3):327-33.

74. Venmans A, Klazen CA, Lohle PN, van Rooij WJ, Verhaar HJ, de Vries J, et al. Percutaneous vertebroplasty and pulmonary cement embolism: results from VERTOS II. AJNR Am J Neuroradiol. 2010;31(8):1451-3.

75. McGirt MJ, Parker SL, Wolinsky JP, Witham TF, Bydon A, Gokaslan ZL. Vertebroplasty and kyphoplasty for the treatment of vertebral compression fractures: an evidenced-based review of the literature. Spine J. 2009;9(6):501-8.

76. Sidhu GS, Kepler CK, Savage KE, Eachus B, Albert TJ, Vaccaro AR. Neurological deficit due to cement extravasation following a vertebral augmentation procedure. J Neurosurg Spine. 2013;19(1):61-70.

77. Abdelrahman H, Siam AE, Shawky A, Ezzati A, Boehm H. Infection after vertebroplasty or kyphoplasty. A series of nine cases and review of literature. Spine J. 2013:13(12):1809-17.

78. Uppin AA, Hirsch JA, Centenera LV, Pfiefer BA, Pazianos AG, Choi IS. Occurrence of new vertebral body fracture after percutaneous vertebroplasty in patients with osteoporosis. Radiology. 2003;226(1):119-24.

79. Grados F, Depriester C, Cayrolle G, Hardy N, Deramond H, Fardellone P. Long-term observations of vertebral osteoporotic fractures treated by percutaneous vertebroplasty. Rheumatology (Oxford). 2000;39(12):1410-4.

80. Diamond TH, Bryant C, Browne L, Clark WA. Clinical outcomes after acute osteoporotic vertebral fractures: a 2-year non-randomised trial comparing percutaneous vertebroplasty with conservative therapy. Med J Aust. 2006;184(3):113-7.

81. Song D, Meng B, Gan M, Niu J, Li S, Chen H, et al. The incidence of secondary vertebral fracture of vertebral augmentation techniques versus conservative treatment for painful osteoporotic vertebral fractures: a systematic review and meta-analysis. Acta Radiol. 2015;56(8):970-9.

82. Sun G, Tang H, Li M, Liu X, Jin P, Li L. Analysis of risk factors of subsequent fractures after vertebroplasty. Eur Spine J. 2014;23(6):1339-45

83. Ma X, Xing D, Ma J, Wang J, Chen Y, Xu W, et al. Risk factors for new vertebral compres sion fractures after percutaneous vertebroplasty: qualitative evidence synthesized from a systematic review. Spine (Phila Pa 1976). 2013;38(12):E713-22. 